\title{
А. А. ДВОРЕЦКИЙ
}

${ }^{1}$ Российская академия народного хозяйства и государственной службы при Президенте Российской Федераичи, 2. Москва, Россия

\section{ЭЛЕКТРОННОЕ ПРАВИТЕАЬСТВО В СОВРЕМЕННОЙ РОССИИ: ИНФРАСТРУКТУРНЫЕ ПРОБАЕМЫ И ПУТИ ИХ РЕШЕНИЯ}

\author{
Дворецкий Андрей Алексеевич, аспирант Высшей школы правоведения Института \\ государственной службы и управления, Российская академия народного хозяйства \\ и государственной службы при Президенте Российской Федерации; помощник \\ адвоката, Международная коллегия адвокатов «Санкт Петербург» \\ Адрес: 119606, Москва, просп. Вернадского, 84, тел.: +7 (499) 956-99-99 \\ E-mail: andrey.dvoretsky@mail.ru \\ ORCID: http://orcid.org/0000-0002-5468-2030 \\ Web of Science Researcher ID: http://www.researcherid.com/rid/U-1774-2018 \\ eLIBRARY ID: AuthorID: 228621
}

Цель: формулирование основных проблем в области организации и функционирования инфраструктуры отечественного механизма электронного правительства и предложение возможных путей их решения.

Методы: системно-структурный подход; диалектический метод, ориентированный на выявление закономерностей динамики процессов или явлений; отчетный метод, позволяющий получать данные из официальных источников; общенаучные методы: анализ, обобщение, абстрагирование, классификация.

Результаты: проведен анализ научных подходов к пониманию электронного правительства, в результате которого систематизированы представления об этом явлении в узком и широком смысле, а также определена необходимость более широкого понимания и использования системы электронного управления. В статье проанализированы модели электронного правительства, а также действующая инфраструктура электронного правительства в России. Исследование состояния отечественной инфраструктуры электронного правительства показало, что в России в целом реализована данная концепция. Между тем в действующем механизме электронного правительства имеются отдельные организационные, финансовые и правовые проблемы. Автором предложены некоторые рекомендации по их решению. Научная новизна: на основе анализа зарубежной и российской литературы, правовых актов и практики их реализации дана оценка современного состояния инфраструктуры электронного правительства в России, а также сформулированы перспективные пути дальнейшего развития электронного правительства на основе устранения недостатков его инфраструктуры.

Практическая значимость: положения статьи могут быть использованы в практической деятельности органов государственной власти при модернизации системы электронного правительства.

Ключевые слова: ИКТ; электронное правительство; инфраструктура электронного правительства; государственные услуги

Конфликт интересов: автором не заявлен.

Как цитировать статью: Дворецкий А. А. Электронное правительство в современной России: инфраструктурные проблемы и пути их решения // Актуальные проблемы экономики и права. 2020. T. 14, № 3. C. 469-486. DOI: http:// dx.doi.org/10.21202/1993-047X.14.2020.3.469-486 


\title{
A. A. DVORETSKIY \\ ${ }^{1}$ Russian Academy for Economy and State Service under the Russian President, Moscow, Russia \\ ELECTRONIC GOVERNMENT IN MODERN RUSSIA: INFRASTRUCTURAL PROBLEMS AND WAYS TO SOLVE THEM
}

\author{
Andrey A. Dvoretskiy, post graduate student of Higher School of Legal Studies of \\ the Institute for State Service and Management, Russian Academy for Economy and \\ State Service under the Russian President; Assistant of an advocate, "Saint Petersburg" \\ International Association of Advocates \\ Адрес: 84 prospekt Vernadskogo, 119606 Moscow, tel.: +7 (499) 956-99-99 \\ E-mail: andrey.dvoretsky@mail.ru \\ ORCID: http://orcid.org/0000-0002-5468-2030 \\ Web of Science Researcher ID: http://www.researcherid.com/rid/U-1774-2018 \\ eLIBRARY ID: AuthorID: 228621
}

Objective: to formulate the main problems in the field of organization and functioning of the infrastructure of the Russian e-government mechanism and to propose the possible ways to solve them.

Methods: system-structural approach; dialectical method aimed at identifying the patterns of the dynamics of processes or phenomena; reporting method, helping to obtain data from official sources; general scientific methods: analysis, generalization, abstraction, classification.

Results: the analysis of scientific approaches to the understanding of e-government is carried out. The main models of interaction between the state, citizens, business, and non-profit organizations are considered, as well as optimization of document circulation and information exchange. The study of the state of the national e-government infrastructure has shown that implementation of this concept has been generally completed in Russia. At the same time, the current e-government mechanism has a number of organizational, financial and legal problems. The author offers some recommendations to solve them, for example, a simpler process of service rendering.

Scientific novelty: based on the analysis of foreign and Russian literature, legal acts and practices of their implementation, the current state of e-government infrastructure in Russia is assessed, and promising ways of e-government further development are formulated based on the elimination of shortcomings in its infrastructure.

Practical significance: the provisions of the article can be used in the practical activities of public authorities to modernize the e-government system.

Keywords: ICT; E-government; E-government infrastructure; Public services

Conflict of Interest: No conflict of interest is declared by the author.

For citation: Dvoretskiy A. A. Electronic government in modern Russia: infrastructural problems and ways to solve them, Actual Problems of Economics and Law, 2020, Vol. 14, No. 3, pp. 469-486 (in Russ.). DOI: http://dx.doi. org/10.21202/1993-047X.14.2020.3.469-486

\section{Введение}

В эпоху интенсивного развития постиндустриального общества, когда стремительно происходит усложнение общественных отношений, электронные технологии становятся неотъемлемым компонентом систем управления во всех отраслях народного хозяйства. В этой связи особую актуальность приобретает повышение качества публичного управления путем активного использования инновационных информационных и коммуникационных техноло- гий (далее - ИКТ). Эта идея положена в основу концепции электронного правительства (далее э-правительства).

Эффективная электронная инфраструктура является основополагающим фактором повышения качества жизни, роста конкурентоспособности экономики. Между тем в 2016 г. по международному индексу сетевой готовности, отражающему уровень зрелости общества в области развития ИКТ, Россия занимала лишь 41-е место после Сингапура, США, 
Нидерландов ${ }^{1}$. Имеющиеся проблемы актуализируют вопрос о необходимости дальнейшей информатизации управления, что в практическом плане означает совершенствование механизма э-правительства ${ }^{2}$.

Концепция э-правительства начала оформляться в странах Западной Европы и Северной Америки в конце 1990-х гг. в качестве теории внедрения ИКТ в работу органов власти с целью повышения эффективности и транспарентности их деятельности $[1$, c. 35]. Однако первые идеи такого использования информационных и коммуникационных технологий зародились еще в 1970-х гг. [2, с. 26]. Данная сфера относительно молодая, что объективно свидетельствует о необходимости ее научного познания [3, с. 315].

На сегодняшний день существует множество определений термина «э-правительство». Так, глоссарий сайта Организации экономического сотрудничества и развития определяет э-правительство как использование ИКТ при исполнении всего спектра государственных функций 3 . Питер Эрнон, Ровена Каллен и Гарольд С. Релей определяют э-правительство как предоставление бизнесу и гражданам правительственных сервисов и информации посредством Интернета [4, с. 5]. В монографии профессора Ричарда Хикса дается следующее определение: любое использование цифровых информационных технологий в государственном секторе [5, с. 2]. Росарио Перес-Моротеа, Каролина Понтонес-Роза и Монтсеррат НуньесЧичарро пишут, что главная цель э-правительства сделать публичные институты более прозрачными и подотчетными [6, с. 1].

Как мы видим, в зарубежной литературе э-правительство рассматривается с разных сторон. Фрэнк Баннистер и Регина Коннолли подсчитали, что с начала 2000-х гг. оно изучалось в контексте 25 различных

Глобальный отчет по информационным технологиям 2016 // Официальный сайт Всемирного экономического форума. URL: http://reports.weforum.org/global-information-technologyreport-2016/infographics-and-shareables/ (дата обращения: 29.04.2020).

2 Digital Government and Open Data Readiness Assessment // Официальный сайт World Bank Group. URL: http://hdl.handle. net/10986/32547 (дата обращения: 29.04.2020).

3 Глоссарий статистических терминов // Официальный сайт Организации экономического сотрудничества и развития. URL: https://stats.oecd.org/Glossary/detail.asp?ID=4752 (дата обращения: 29.04.2020). теорий, среди которых теории систем, бюрократии, рационального выбора, общественной ценности; институциональная, культурная теории и даже теория игр [7, с. 7]. Недостатком многих подходов является невысокая степень конкретизации либо непозволительное сужение содержания э-правительства. Комплексной теории к сегодняшнему дню не выработано.

Определение э-правительства лишь как альтернативного способа предоставления услуг, как перехода на безбумажный документооборот, как повышения открытости управления так же неправильно, как и неоправданное расширение этого термина: э-правительство - явление комплексное. В этой связи И. Ю. Богдановская заметила, что сводить э-правительство лишь к созданию коммуникативной инфраструктуры, позволяющей власти и гражданам взаимодействовать, недопустимо [8].

Оригинален подход шведского ученого Лейфа Сундберга. Он выделяет три сферы деятельности правительства: государственное управление, формальная политика, гражданское общество. Автор выделяет три концепции: на стыке государственного управления и гражданского общества э-правительство понимается как оказание электронных услуг; на стыке государственного управления и формальной политики - как управление с активным использованием ИКТ; на стыке формальной политики и гражданского общества - как электронная демократия (внедрение ИКТ в избирательные процессы) [9, с. 22-23]. Такое триединое понимание э-правительства характерно для многих исследований [10, с. 720]. Но если с первыми двумя составляющими можно согласиться, то электронная демократия, на наш взгляд, не может являться компонентом э-правительства. Электронная демократия заключает в себе онлайн-голосование, электронное участие граждан в принятии решений и т. п. $[11$, с. 6]. Тогда как э-правительство характеризует исполнительную деятельность государства, которую осуществляет правительство. С точки зрения Л. Сундберга получается, что э-правительство - то же самое, что электронное государство. Однако исполнительная власть - один из видов государственной деятельности. Значит, включение электронной демократии в состав э-правительства логически неверно.

Е. Г. Иншакова рассматривает э-правительство в рамках административно-правового подхода: «Система взаимосвязанных и взаимодействующих между 
собой административно-правовых институтов ${ }^{4}$, входящих в общий механизм административно-правового регулирования и обеспечивающих как электронное взаимодействие внутри системы исполнительных органов государственной власти при исполнении государственных функций, так и прав, свобод и законных интересов физических лиц и организаций в сфере предоставления публичных услуг» [12, с. 18]. В данном случае исследователь сконцентрировался именно на системе органов исполнительной власти, не подменяя «э-правительство» более широким понятием «электронное государство».

В России определение э-правительства было закреплено в Концепции формирования в Российской Федерации электронного правительства до 2010 г., согласно которой э-правительство - это новая форма организации деятельности органов власти, обеспечивающая за счет применения ИКТ качественно новый уровень оперативности и удобства получения государственных услуг и информации о деятельности публичных органов 5 . Схожие определения приводят И. Л. Бачило [13, с. 310], Д. А. Баранов и А. С. Ямщиков [14].

Таким образом, в России э-правительство понимается в узком смысле: как использование ИКТ для предоставления услуг. Об этом свидетельствует и тот факт, что закон, который содержит нормы об основных компонентах э-правительства (государственные порталы, реестры услуг, система электронного взаимодействия), носит название «Об организации предоставления государственных и муниципальных услуг» ${ }^{6}$.

Интересно определение Г. Л. Акопова: э-правительство - это «метафора, обозначающая информационное взаимодействие органов государственной

\footnotetext{
4 Например, формы и методы публичного управления, государственная служба, правовые акты управления, административные процедуры, административные регламенты, исполнение государственных функций и предоставление публичных услуг.

5 Распоряжение Правительства Российской Федерации от 06.05.2008 № 632-р «О Концепции формирования в Российской Федерации электронного правительства до 2010 года» // Собрание законодательства Российской Федерации. 2008. № 20. Ст. 2372.

6 Федеральный закон от 27.07.2010 № 210-Ф3 «Об организации предоставления государственных и муниципальных услуг» // Собрание законодательства Российской Федерации. 2010. № 31. Ст. 4179.
}

власти и общества с использованием ИКТ» [15]. Похожий тезис нашел свое отражение и в статье П. У. Кузнецова, который отмечает: «...термин “электронное правительство" лингвистически трудно определить, поскольку слова “электронное” и “правительство" никак синтаксически не связываются в силу их существенных семантических различий... В понятии “электронное правительство” объединены два пространства: физико-техническое и социальное» [16, с. 42]. Авторы верно подметили умозрительноабстрактный характер концепции э-правительства. Действительно, феномен э-правительства нематериален, но в то же время эта концепция материализуется в конкретно-прикладных вещах: сайты органов власти, интернет-порталы, программное обеспечение, информационные системы и т. п.

Схожей позиции придерживаются Ю. М. Акаткин и Е. Д. Ясиновская, которые определяют э-правительство как сложную социотехническую систему, т. е. спроектированную систему, включающую комбинацию технических и человеческих элементов $[17$, c. 28]. Между тем в отличие от Акопова и Кузнецова авторы выразили инструментально-технический подход, видя в э-правительстве скорее физико-техническую систему, чем теоретическую модель.

Таким образом, в науке сложилось узкое и широкое понимание термина «э-правительство». Э-правительство в узком смысле рассматривается как одна из технологий государственного управления, которые «отражают процесс, т. е. совокупность управленческих действий, совершаемых в определенной последовательности» [18, с. 140]. В данном случае исследователи придерживаются «сервисного» подхода и определяют э-правительство как форму предоставления публичных услуг населению с помощью ИКТ. Так, В. М. Трегубова пишет: «...электронное правительство не является дополнением или аналогом традиционного правительства, а лишь определяет новый способ взаимодействия на основе активного использования ИКТ в целях повышения эффективности предоставления государственных услуг» [19, с. 279]. Аналогичного мнения придерживаются Ю. С. Булгатова и А. В. Дырхеев [20, с. 11], Е. В. Мандрыка [18, с. 142], Д. В. Чумаков [21, с. 69].

В широком понимании э-правительство - это качественно новая форма государственного управления, характерная для информационного общества и ос- 
нованная на применении организационно-управленческих инноваций. Этот подход разделяют Е. А. Кашина [22, с. 13], А. Ронки [23, с. 11], А. А. Сидорова $[24$, с. 14$]$, В. В. Солодов [25, с. 51].

Отличие приведенных подходов состоит в следующем: первый предполагает изменение лишь формы осуществления управленческих функций, но не затрагивает их содержания; ИКТ рассматриваются лишь как ресурс, используемый для оказания услуг. Очевидно, что простое использование ИКТ не может привести к качественным изменениям: «...приобретение любого количества компьютеров и серверов, установка “проводов" и программного обеспечения сама по себе не оказывает практически никакого позитивного воздействия на эффективность и качество государственного управления. С этой точки зрения главное при создании “электронного правительства” это изменение типа деятельности самих органов государственной власти: менталитета руководителей и рядовых госслужащих, административных регламентов, системы обучения госслужащих» [26, с. 7]. Поэтому более актуален второй подход, предполагающий создание новой (инновационной) модели управления, которая заключается в трансформации иерархобюрократических структур в адаптивные системы, направленные на оптимизацию, рационализацию и повышение эффективности администрирования $[27$, с. 12]. Эта идея образует стержень современной концепции э-правительства.

Заметим, что в современной литературе выделяются несколько моделей э-правительства. Мы не ставим целью изучать особенности каждой модели, однако считаем должным упомянуть их: англо-американская; континентально-европейская; азиатская и российская. Эта типология предлагается Р. А. Лапочкиным [28, с. 132], Е. С. Някиной и Е. А. Погодиной [29, с. 181], А. Э. Османовым [30, с. 114], М. А. Сединкиным [31, с. 349] и др.

Итак, концепция э-правительства предполагает трансформацию публичного управления путем активного внедрения ИКТ в деятельность органов власти, в процессы их взаимодействия с населением и между собой во имя повышения эффективности исполнительно-распорядительной деятельности, качества услуг, улучшения деловой среды; обеспечения таких социальных ценностей, как демократизм, прозрачность и участие [32, с. 168].

\section{Результаты исследования}

Прежде чем перейти к анализу современного состояния инфраструктуры отечественного э-правительства, следует осветить вопрос о типах взаимодействия в структуре э-правительства.

Ядром всех определений э-правительства является идея использования ИКТ для повышения эффективности процессов взаимодействия. Данный концепт лежит в основе выделения основных моделей взаимодействия ведущих акторов: государства, граждан, бизнеса и некоммерческих организаций (рис. 1).

На приведенной схеме буквой $G$ (government) обозначен орган власти, $C$ (citizen, costumer) - гражданин (потребитель), B (business) - бизнес, $N$ (non-profit organization, $N G O)$ - некоммерческая организация (далее - HКО), E (employee) - государственный служащий. Стрелками обозначены направления взаимодействия.

Модель Government-to-Citizen (G2C) включает в себя предоставление услуг (например, выдачу или замену паспорта, получение свидетельства о рождении, о заключении брака, подачу налоговых деклараций и т. п.) и распространение среди населения информации о них. Помимо этого, модель $G 2 C$ предполагает реализацию различных форм гражданского участия в разработке и принятии управленческих решений. Так, благодаря порталу «Активный гражданин» Правительства Москвы (https://ag.mos.ru/) жители города могут участвовать в голосованиях по вопросам транспортной инфраструктуры, благоустройства городских территорий, организации здравоохранения и образования и т. п. Платформой взаимодействия органов власти с гражданами в рамках э-правительства являются специальные государственные порталы, служащие агрегаторами всех государственных услуг (например, в Австралии - https://www.australia.gov.au/, в Великобритании - https://www.gov.uk/, в России https://www.gosuslugi.ru/, в Сингапуре - https://www. gov.sg/, в США - https://www.whitehouse.gov/, в Казахстане - https://www.e-gov.kz, в Эстонии - https:// www.eesti.ee/et/ и т. д.).

Модель Government-to-Business (G2B) предполагает взаимодействие между органами публичной власти и коммерческими организациями. Этот тип взаимодействия представлен механизмами электронной коммерции, управления закупками для государственных нужд. Транзакции типа $G 2 B$ и $B 2 G$ включают 


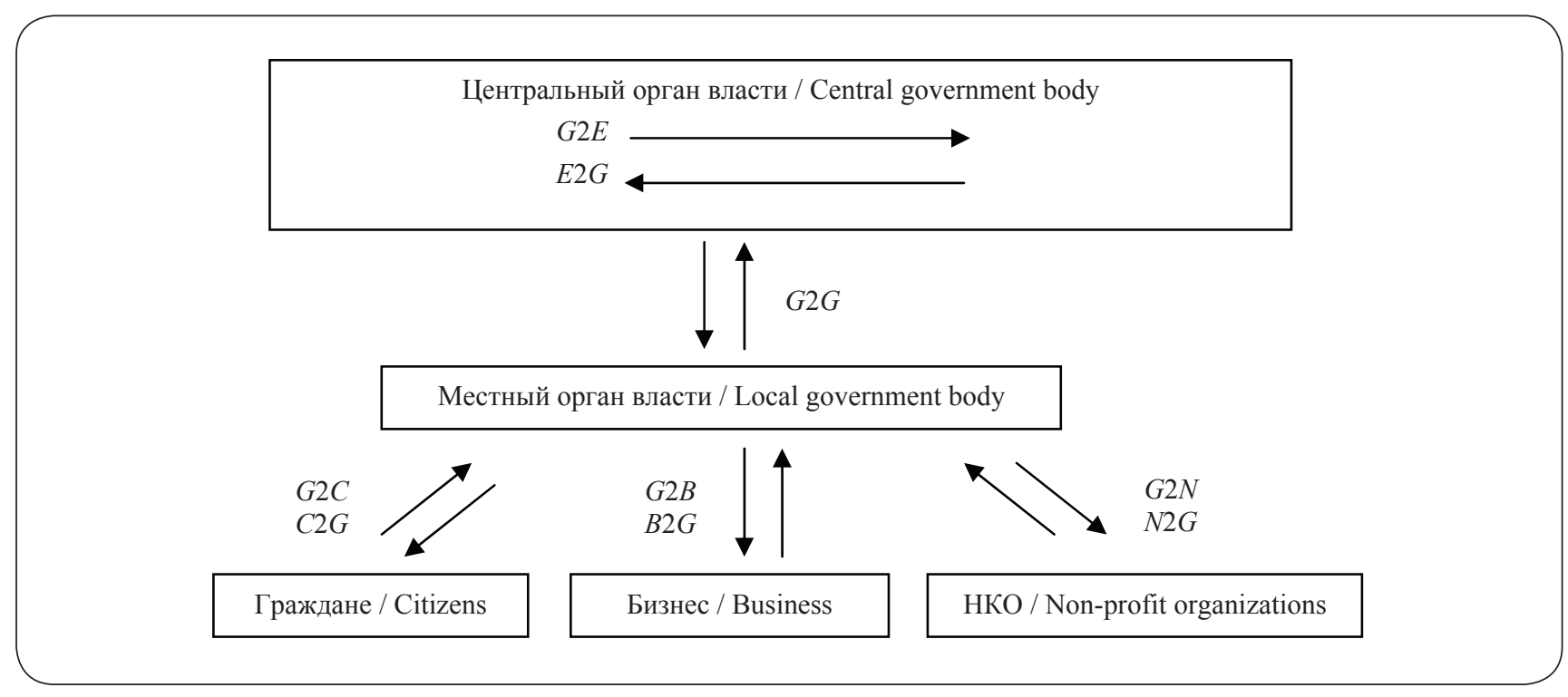

Рис. 1. Схема взаимодействия органов власти с гражданами, бизнесом и некоммерческими организациями

Источник: составлено автором на основе анализа научной литературы и публикаций $[17,33-35]$.

Fig. 1. Interaction of government bodies with citizens, business and non-profit organizations

Source: compiled by the author based on analysis of scientific publications [17, 33-35].

в себя различные услуги, которыми обмениваются правительство и бизнес-сообщество, включая получение текущей информации о бизнес-климате в стране, получение и продление лицензий, разрешений, регистрацию юридических лиц, подачу налоговых деклараций.

Модель Government-to- $N G O(G 2 N)$ включает в себя обмен информацией в отношении административных актов и стратегий, сведений, регистров, законов, политических программ, справочных данных для решений и т. д. [17, с. 30]. С 2006 г. в России развитию данного типа взаимодействия уделяется большое внимание. Именно тогда была создана единая интернет-площадка для поддержки социально значимых проектов, разрабатываемых НКО, путем распределения грантов - Фонд президентских грантов (https://президентскиегранты. pф/). На этом сайте НКО может подать заявку на участие собственного проекта в конкурсе по распределению грантов. После успешного прохождения независимой экспертизы организация получает деньги, которые обязана потратить на реализацию своего проекта.

Модель Government-to-Government (G2G) предусматривает взаимодействие органов публичной власти как по вертикали (т. е. между органами различных административно-управленческих уровней), так и по горизонтали (обмен информацией между органами в пределах одного уровня иерархии). Инструментами взаимодействия в рамках данной модели являются системы электронного документооборота (например, СЭД «Дело», СЭД Directum, Программный комплекс «1С: Документооборот государственного учреждения 8» и др.), географические информационные системы (например, «Панорама», MosMap-GIS, «ПроГео» и др.), системы поддержки принятия решений, основанные на нейронных сетях и искусственном интеллекте (например, OLAP-системы, Data Mining, Oracle и др.).

Модель Government-to-Employee (G2E) заключается во взаимодействии между государством и государственными служащими, позволяет сократить бумажный документооборот путем перевода его в электронную форму; сократить временные издержки за счет автоматизации и оптимизации административных действий и процедур; согласовать взаимодействие с другими структурами за счет использования системы межведомственного электронного взаимодействия. 
Выделение перечисленных типов взаимодействий важно, поскольку по степени соответствия реальной технологической инфраструктуры э-правительства названным теоретическим моделям можно судить об оправданности наличия отдельных элементов данной инфраструктуры и о ее эффективности в целом.

Под инфраструктурой э-правительства понимается совокупность государственных информационных систем, программно-аппаратных средств и сетей связи, обеспечивающих взаимодействие власти, граждан, организаций при предоставлении услуг и исполнении публичных функций ${ }^{7}$.

Инфраструктура э-правительства, как и структура любой сервисной организации, представляется в виде взаимосвязанных фронт-офиса и бэк-офиса. Фронтофис представляет собой внешние взаимодействия в системе электронного правительства; заявители могут лицезреть его, подавая заявки на оказание услуги и получая результаты ее исполнения. Бэк-офис относится к внутрисистемным взаимодействиям, где производятся прием и контроль правильности оформления заявок и готовятся результаты их выполнения. В бэкофисе электронного правительства находится множество информационных систем, к которым заявители не имеют непосредственного доступа. Ключевая идея такого разделения заключается в том, чтобы развести механизм обращения за услугой и процесс принятия решения и фиксации результата с целью минимизации риска возникновения коррупционных факторов.

Главный технологический элемент фронт-офиса электронного правительства - государственный портал - вид сайта, являющийся информационной системой, которая «обеспечивает пользователям единый авторизованный персонифицированный доступ к внутренним и внешним информационным ресурсам» [24, с. 41]. Функция портала - обеспечить дистанционное взаимодействие граждан с органами власти.

Весьма проблемным вопросом является отсутствие четкого определения структурных элементов бэк-офиса электронного правительства: ни правовые акты, ни научные публикации не называют четкой системы компонентов бэк-офиса э-правительства.

\footnotetext{
7 Стратегия развития информационного общества в Российской Федерации на 2017-2030 годы, утвержденная Указом Президента Российской Федерации от 09.05.2017 № 203 // Собрание законодательства Российской Федерации. 2017. № 20. Ст. 2901.
}

На основе анализа документов в этой сфере предлагается относить к инфраструктуре э-правительства следующие элементы:

I. Инфраструктура взаимодействия информаиионных систем:

1. Федеральные государственные информационные системы (ФГИС):

1.1. ФГИС «Единый портал государственных услуг» (ЕПГУ).

1.2. ФГИС «Федеральный реестр государственных и муниципальных услуг (функций)» (ФРГУ).

1.3. Система межведомственного электронного документооборота (МЭДО).

1.4. ФГИС «Единая система межведомственного электронного взаимодействия» (далее - СМЭВ).

1.5. ФГИС «Единая система идентификации и аутентификации в инфраструктуре, обеспечивающей информационно-технологическое взаимодействие информационных систем, используемых для предоставления государственных и муниципальных услуг в электронной форме» (далее - ЕСИА).

1.6. ФГИС «Единая система нормативной справочной информации» (ЕСНСИ).

1.7. ФГИС, обеспечивающая процесс досудебного (внесудебного) обжалования решений и действий (бездействия), совершенных при предоставлении государственных и муниципальных услуг (ДО).

1.8. ФГИС «Федеральный ситуационный центр электронного правительства» (ФСЦ ЭП).

1.9. Иные ФГИС.

2. Региональные государственные информационные системы.

3. Муниципальные информационные системы.

4. Информационные системы органов власти, организаций, участвующих в предоставлении услуг.

5. Система открытого правительства, компоненты которой реализуются на государственных сайтах.

II. Техническая инфраструктура:

1. Центры обработки данных (технические средства предоставления вычислительной мощности для размещения информационных систем).

2. Сеть передачи данных.

3. Система обеспечения информационной безопасности.

Кроме перечисленных выше информационных систем, существует множество других, например Государственная интегрированная информационная 
система управления общественными финансами «Электронный бюджет» (федеральный оператор Минфин России $)^{8}$, Государственная информационная система о государственных и муниципальных платежах (оператор - Федеральное казначейство) ${ }^{9}$, Государственная автоматизированная система «Управление» (операторы - Федеральное казначейство и ФСО России $)^{10}$, Единая информационная система в сфере закупок (оператор - Федеральное казначейство) $)^{11}$ и т. д. Согласно Порталу открытых данных (data.gov. ru), в России функционирует 340 федеральных и более 2000 региональных информационных систем ${ }^{12}$.

Мощный рывок в развитии э-правительства Россия совершила в 2012 г., поднявшись с 59-е на 27-е место. В 2018 г. Россия занимала 32-е место, уровень развития российского э-правительства оценен как очень высокий. Динамика изменения данного показателя представлена на рис. 2.

Сегодня важно не только поддерживать достигнутые результаты, но и активно совершенствовать отечественную модель э-правительства. В этой области существует большое количество проблем: нормативноправовых, методических, технико-технологических, финансово-экономических, информационных, образовательно-профессиональных и т. д. В рамках настоящей статьи рассмотрены некоторые проблемы, связанные с построением и функционированием инфраструктуры э-правительства в России. Указанные проблемы составляют группу технико-технологических проблем.

\footnotetext{
8 Положение о государственной интегрированной информационной системе управления общественными финансами «Электронный бюджет», утвержденное Постановлением Правительства Российской Федерации от 30.06.2015 № 658 // Собрание законодательства Российской Федерации. 2015. № 28. Ст. 4228.

9 Федеральный закон от 27.07.2010 № 210-Ф3 «Об организации предоставления государственных и муниципальных услуг» // Собрание законодательства Российской Федерации. 2010. № 31. Ст. 4179.

${ }^{10}$ Постановление Правительства Российской Федерации от 25.12.2009 № 1088 «О государственной автоматизированной информационной системе „Управление“» // Собрание законодательства Российской Федерации. 2010. № 1. Ст. 101.

${ }^{11}$ Правила функционирования единой информационной системы в сфере закупок, утвержденные Постановлением Правительства Российской Федерации от 23.12.2015 № 1414 // Собрание законодательства Российской Федерации. 2016. № 2. Ст. 324.

${ }^{12}$ Портал открытых данных Российской Федерации. URL: https://data.gov.ru/opendata/7708660670-reestr-fgis (дата обращения: 29.04.2020)
}

Первая выявленная проблема заключается в том, что при получении государственной услуги на заявителя ложится бремя совершения множества сопутствующих юридически значимых действий (регистрация, получение справок, разрешений, свидетельств). Кроме того, многие публичные услуги последовательно связаны друг с другом. Так, когда у молодой семьи рождается ребенок, родители должны получить свидетельство о рождении, страховой номер индивидуального лицевого счета, прикрепиться к детской поликлинике, заявить о получении всех полагающихся по закону социальных выплат и пр. Очевидно, что гораздо удобнее было бы создать для заявителя возможность одним заявлением получить, кроме основной, еще и сопутствующие услуги. Сегодня для этого государство располагает необходимыми техническими инструментами (в частности, скоростным обменом юридически значимой информацией между органами публичной власти) для сведения к минимуму количества обязательных действий, совершаемых заявителем.

Данную проблему можно решить путем создания так называемых суперсервисов. Суперсервис - это государственный сервис по комплексному оказанию услуг в соответствии с жизненной ситуацией заявителя ${ }^{13}$. Для конструирования суперсервиса выделяется типичная жизненная ситуация (например, рождение ребенка, оформление европротокола, выход на пенсию и т. п.), объединяющая в себе несколько государственных услуг.

Суперсервисы должны строиться на следующих принципах:

1) экстерриториальность (получение услуги независимо от места регистрации гражданина);

2) омниканальность (получение услуги, технической поддержки и оценки качества в одном канале, через ЕПГУ);

3) безбумажный документооборот;

${ }^{13}$ По существу, суперсервис является воплощенным в электронную форму видом комплексного запроса. Комплексный запрос - предоставление нескольких государственных и (или) муниципальных услуг при однократном обращении заявителя с таким запросом (Федеральный закон от 27.07.2010 № 210-Ф3 «Об организации предоставления государственных и муниципальных услуг» // Собрание законодательства Российской Федерации. 2010. № 31. Ст. 4179). 


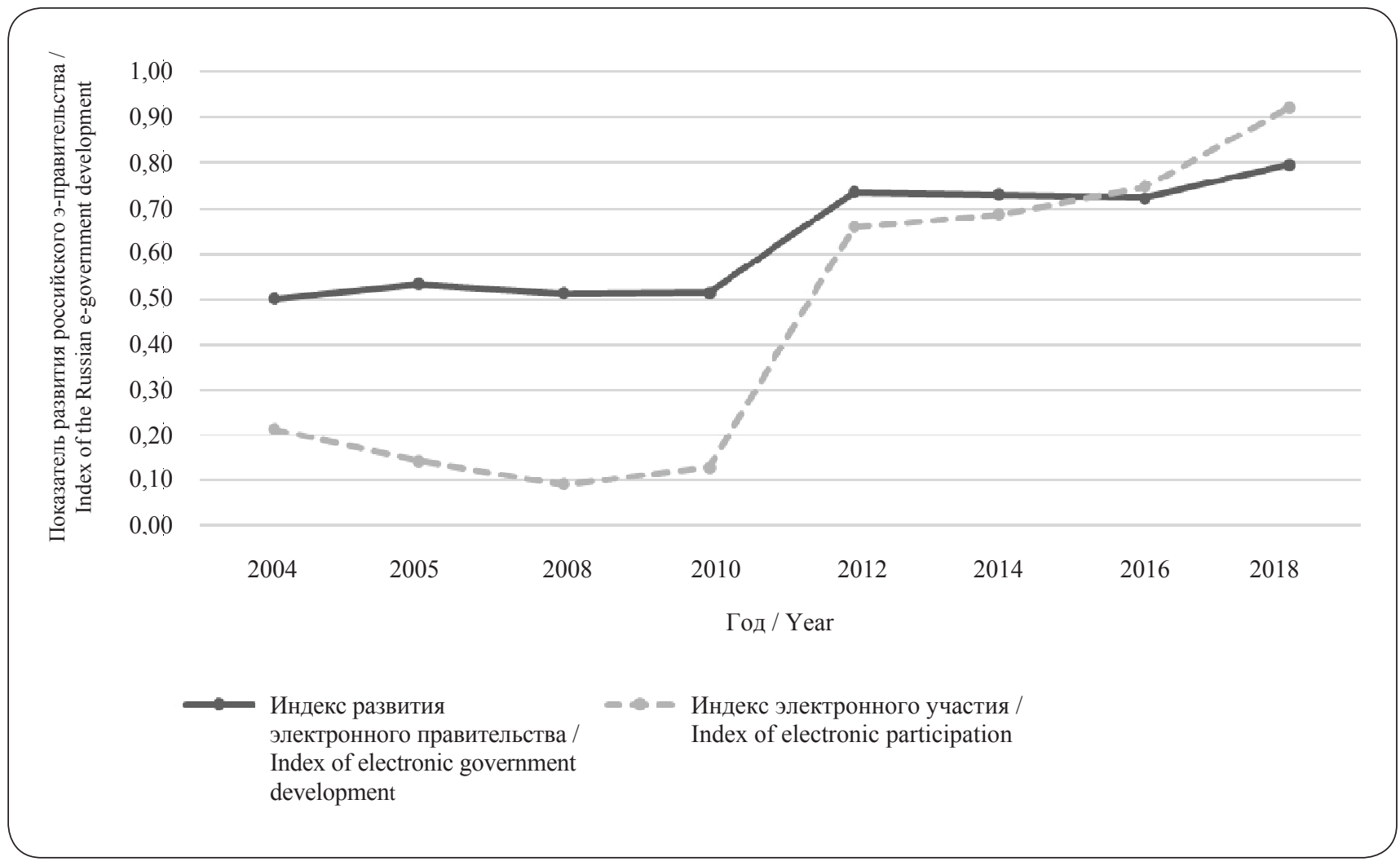

Рис. 2. Позиция России в рейтинге ООН по уровню развития э-правительства

Источник: составлено автором на основе Обзоров ООН по электронному правительству за период с 2004 по 2018 г. URL: https://publicadministration.un.org/ru/Research/UN-e-Government-Surveys (дата обращения: 29.04.2020).

\section{Fig. 2. Russia in the UNO ranking of electronic government development}

Source: compiled by the author based on UNO surveys on electronic government from 2004 to 2018, available at:: https:// publicadministration.un.org/ru/Research/UN-e-Government-Surveys (access date: 29.04.2020).

4) автоматизация процессов (минимизация участия человека при принятии решения);

5) проактивность (оказание услуги без заявления, когда гражданин получает уведомление о полагающихся ему услугах. Актуально при замене паспорта по достижении определенного возраста; при наличии полагающихся субсидий, льгот).

31 января 2018 г. Правительственной комиссией по цифровому развитию, использованию информационных технологий для улучшения качества жизни и условий ведения предпринимательской деятельности одобрен перечень 25 приоритетных суперсервисов, которые заключают в себе около 200 отдельных государственных, муниципальных и негосударственных (в частности, банковских) услуг [36, с. 56].
Из табл. 1 видно, что государство ориентировано на создание суперсервисов, обслуживающих отношения преимущественно Government-to-Citizen (17 из 25 суперсервисов). Между тем, если государство ставит целью развитие малого и среднего бизнеса и активизацию частной инициативы, необходимо снижать трансакционные издержки, в том числе временные и денежные затраты на взаимодействие с органами власти. Следовательно, увеличение количества суперсервисов, обслуживающих связи Government-to-Business, облегчит форму взаимодействия бизнеса и государства и повысит качество такого взаимодействия. Например, можно создать специальный суперсервис, посвященный государственно-частному партнерству (заключение концессионных соглашений, инвестиционных до- 
Распределение перспективных суперсервисов

по типам взаимодействий в инфраструктуре э-правительства

Table 1. Distribution of prospective superservices by the types of interaction in the infrastructure of e-government

\begin{tabular}{|c|c|}
\hline $\begin{array}{c}\text { Суперсервисы, обслуживающие взаимодействия Government-to-Citizen / } \\
\text { Superservices providing Government-to-Citizen interactions }\end{array}$ & $\begin{array}{l}\text { Суперсервисы, обслуживающие взаимодействия } \\
\text { Government-to-Business / } \\
\text { Superservices providing Government-to-Business interactions }\end{array}$ \\
\hline 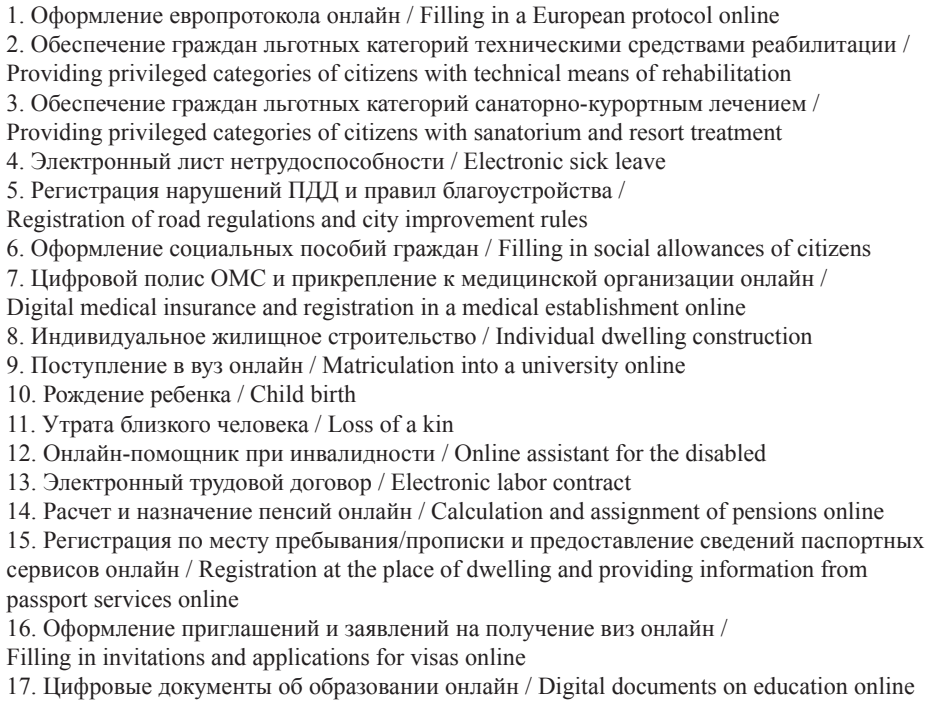 & $\begin{array}{l}\text { 1. Господдержка бизнеса / State support of business } \\
\text { 2. Регистрация бизнеса / Registration of business } \\
\text { 3. Разрешения для бизнеса в цифровом виде / Digital permissions } \\
\text { for business } \\
\text { 4. Безбумажные перевозки пассажиров и грузов / Paperless } \\
\text { transportation of passengers and cargo }\end{array}$ \\
\hline \multicolumn{2}{|c|}{$\begin{array}{l}\text { 1. Цифровое исполнительное производство / Digital executive procedure } \\
\text { 2. Правосудие онлайн (мировые судьи) / Justice online (magistracy) } \\
\text { 3. Уведомление и обжалование штрафов онлайн / Notifying and appealing fines online } \\
\text { 4. Подача заявлений в правоохранительные органы онлайн / Submitting claims to law enforcement bodies online }\end{array}$} \\
\hline
\end{tabular}

Источник: составлено автором на основе данных официального сайта издания «Коммерсантъ». URL: https://www.kommersant.ru/ doc/3773075 (дата обращения: 30.04.2020).

Source: compiled by the author based on the data of an official website of "Kommersant" edition, available at: https://www.kommersant.ru/ doc/3773075 (access date: 30.04.2020).

говоров, соглашений о разделе продукции, соглашений о государственно-частном партнерстве и др.). На наш взгляд, положительный эффект имел бы суперсервис, обслуживающий отношения государства и резидентов особых экономических зон.

Вторая техническая проблема состоит в наличии большого числа документов, условием действительности которых является обязательное наличие бумажного носителя при их предъявлении. Недостатки бумажного документооборота заключаются в накоплении большого числа бумажных документов, в значительных расходах на их хранение, систематизацию, учет и перемещение, в риске их утраты.

Кроме того, удобство оказания публичных услуг предполагает отсутствие необходимости лично по- сещать ведомство. Количество электронных услуг составляет сегодня более 360. Однако имеется множество услуг, результат оказания которых нельзя получить в электронном виде. Это обусловливает сравнительно невысокое положение России в рейтинге качества услуг: в 2017 г. Россия заняла лишь 40-е место среди 190 государств ${ }^{14}$.

14 Доклад «О предоставлении государственных и муниципальных услуг через многофункциональные центры и внедрении механизма оценки их качества» // Официальный сайт Министерства экономического развития Российской Федерации. URL: http://economy.gov.ru/minec/about/structure/depgosgv/2017040505 (дата обращения: 29.04.2020). 
Описанная проблема может быть решена путем внедрения так называемой реестровой модели. Реестровая модель позволит увеличить количество услуг в электронной форме и упростить процесс их оказания, поскольку результат услуги представляет собой внесение изменений в публичный свод достоверных сведений - реестр, а не выдачу бумажного документа. Реестр доступен для органов власти и общественности, поскольку именно запись в публичном реестре имеет юридическое значение.

Положительный опыт реализации реестровой модели уже имеется в России (ЕГРЮЛ, ЕГРН, реестры, которые ведет Росаккредитация и др.). С 1 января 2021 г. реестровая модель будет внедрена в сферу лицензирования отдельных видов деятельности ${ }^{15}$. Предоставление лицензии в бумажном виде будет заменено внесением записи в электронный реестр лицензий, что является подтверждением права на осуществление лицензируемого вида деятельности. Проверка лицензии будет полностью автоматизирована; получение электронной выписки из реестра на первое время предполагается сделать безвозмездным. Данные меры сократят бюрократизм и сделают лицензии нефальсифицируемыми, что, по нашему мнению, наиболее благоприятно скажется, прежде всего, на взаимодействиях Government-to-Business и Government-to-NGO, поскольку интенсивный документооборот характерен именно для деятельности юридических лиц. Могут быть переведены в реестровый формат свидетельство об исключительном праве на наименование места происхождения товара, свидетельство об аккредитации в качестве подразделения транспортной безопасности и др.

Также необходимо активизировать работу по переводу на реестровую модель государственных услуг в рамках отношений Government-to-Citizen: выдачу водительского удостоверения, страхового свидетельства, свидетельства об установлении отцовства и т. п. Для этих целей требуется внести изменения в соответствующее законодательство.

\footnotetext{
${ }^{15}$ Федеральный закон от 27.12.2019 № 478-Ф3 «О внесении изменений в отдельные законодательные акты Российской Федерации в части внедрения реестровой модели предоставления государственных услуг по лицензированию отдельных видов деятельности» // Собрание законодательства Российской Федерации. 2019. № 52. Ст. 7796.
}

Следующую проблему можно назвать «webфеодализм». Сегодня существует более 5000 сайтов органов власти, более 130 порталов, более 330 информационных систем. При таких условиях, а также в отсутствие единых стандартов дизайна и организации данных поиск информации затруднен. В научной литературе зачастую отмечается: отсутствие удобного и доступного интерфейса связано с тем, что интернет-сервисы разрабатывались с точки зрения самих менеджеров, а не пользователей [37, с. 820]. «Web-феодализм» способствует снижению эффективности процесса принятия решений. Проблема разрозненности государственного интернет-пространства осложняет большинство взаимодействий государства с внешними субъектами (Governmentto-Citizen, Government-to-Business и Government-to$N G O)$, поскольку граждане, бизнес и некоммерческий сектор вынуждены вступать в отношения с органами публичной власти.

Для решения этой проблемы следует создать единую точку доступа ко всем государственным ресурсам, которая предусматривала бы трансформацию разрозненного web-пространства государства в сторону роста его полезности и удобства для пользователей. Единая платформа должна включать в себя систематизированные интернет-порталы, сайты, приложения, которые используются для взаимодействия государства с гражданами, бизнесом и НКО. Пользователям должна быть предоставлена возможность мгновенного доступа к государственным сервисам. Таким образом, будет создано «одно окно» для общения граждан и бизнеса с государством.

Для реализации этого проекта целесообразно обратиться к опыту зарубежных стран. Так, в Великобритании функционирует единый портал https:/ www.gov.uk/, на котором обеспечено присутствие 25 департаментов и свыше 385 учреждений, сосредоточены более 7700 услуг, публикуются материалы по значимым темам ${ }^{16}$. Портал отличает интуитивная доступность и систематизированность информации. Аналогичные порталы существуют в Австралии (https://www.australia.gov.au/), Эстонии (https://www. eesti.ee/et/) и др.

\footnotetext{
${ }^{16}$ Официальный портал государственных услуг Великобритании GOV.UK. URL: https://www.gov.uk/ (дата обращения: 29.04.2020).
} 
Попытка создать нечто подобное в России предпринята в 2016 г.: запущен единый каталог государственных сайтов «Госбар» (http://gosbar.gosuslugi.ru/), содержащий официальные интернет-ресурсы, посвященные деятельности 21 министерства, 62 других ведомств и еще 11 сайтов ${ }^{17}$. На «Госбар» все сервисы сгруппированы в 15 категорий: государственные услуги; здоровье, спорт, туризм; правосудие, порядок; безопасность страны, образование, наука, культура, труд, соцзащита; экономика, финансы; транспорт и др. Выбирая интересующую категорию, пользователь может перейти на сайт любого ведомства. Однако данный сервис по своим возможностям несопоставим с зарубежными порталами, поскольку он является лишь навигационной панелью для перехода по гиперссылкам на сайты государственных сервисов, но не обеспечивает единую точку доступа к самим услугам.

При реализации предыдущих решений государство неизбежно столкнется с еще одной инфраструктурной проблемой - отсутствием единой государственной базы данных, к которой имели бы оперативный доступ все органы публичной власти, участвующие в предоставлении услуг. В этой связи необходимо создать единую облачную цифровую платформу обеспечения оказания услуг, под которой понимается комплекс информационных систем, служащий для предоставления органами власти услуг по модели облачных вычислений, т. е. ИКТ, обеспечивающих повсеместный дистанционный доступ к данным с минимальными затратами на техническую эксплуатацию ${ }^{18}$. В сущности, такая платформа представляет собой виртуальную среду для взаимодействия всех субъектов предоставления услуг: органов власти, организаций и граждан.

Данное решение оптимизирует взаимодействия типа Government-to-Government и Government-toEmployee. Платформа позволит заменить собой Систему межведомственного электронного взаимодействия (СМЭВ) [38, с. 45], поскольку ее преимущества очевидны: для взаимодействия в облаке нет необходимости создавать отдельные базы данных

\footnotetext{
${ }^{17}$ Каталог государственных сайтов «Госбар». URL: http:// gosbar.gosuslugi.ru/ru/ (дата обращения: 29.04.2020).

${ }^{18}$ Стратегии развития информационного общества в Российской Федерации на 2017-2030 годы, утвержденной Указом Президента Российской Федерации от 09.05.2017 № 203 // Собрание законодательства Российской Федерации. 2017. № 20. Ст. 2901.
}

для каждого информационного ресурса, а это, в свою очередь, ведет к сокращению затрат на оборудование и программное обеспечение.

По данным ПАО «Ростелеком», реализация проекта по созданию цифровой облачной платформы позволит в 30 раз сократить затраты на внедрение новых информационных систем и в пять раз сократить сроки внедрения этих систем ${ }^{19}$.

Отдельные технические сложности связаны с идентификацией и аутентификацией пользователей, которые осуществляются при помощи ФГИС «Единая система идентификации и аутентификации». Отметим, что в некоторых зарубежных странах функционируют аналогичные системы. Так, в США роль такой системы выполняет Login.gov ${ }^{20}$, в Великобритании GOV.UK Verify ${ }^{21}$. Существенным достоинством этих систем по сравнению с российской ЕСИА является возможность дистанционного подтверждения личности. В ЕСИА для этого необходима личная явка в один из центров обслуживания (МФЦ, отделение Пенсионного фонда России, отделение ПАО «Сбербанк» и др.), что доставляет серьезные неудобства особенно для маломобильных граждан (лиц пожилого возраста, инвалидов). В США и Великобритании существуют специальные сертифицированные компании, которые проводят проверку личности на основе собственных методов, личная явка пользователя при этом не требуется. В этой связи целесообразно создать в России сеть аккредитованных центров, уполномоченных гарантированно подтверждать личность пользователя без его явки в центр обслуживания ЕСИА и без обмена бумажными документами.

Другим направлением совершенствования ЕСИА является создание платформы биометрической идентификации и аутентификации. Сегодня для идентификации пользователя используются логин и пароль, которые необходимо вводить вручную. В целях повышения уровня пользовательского комфорта, а также исключения вероятности потери, кражи, подделки

\footnotetext{
${ }^{19}$ Национальная облачная платформа // Официальный сайт ПАО «Ростелеком». URL: https://www.company.rt.ru/projects/o7/ (дата обращения: 29.04.2020).

20 Официальный сайт системы «Login.gov». URL: https:// www.login.gov/ (дата обращения: 29.04.2020).

${ }^{21}$ Официальный сайт системы GOV.UK Verify. URL: https:// www.gov.uk/government/publications/introducing-govuk-verify/ introducing-govuk-verify (дата обращения: 29.04.2020)
} 
пароля необходимо реализовать доступ в ЕСИА с применением средств биометрической идентификации и аутентификации.

Иногда под биометрией понимают сбор биологических данных путем накопления изображений человека, когда он находится в общественном месте [39, с. 843]. С таким подходом согласиться нельзя, поскольку он сосредоточивается лишь на возможности сбора биометрических данных вне зависимости от воли граждан. В таком разрезе биометрические данные могут использоваться, например, для поиска правонарушителей. В любом случае приведенное определение отражает скорее лишь одну из сфер применения биометрических данных. Более корректно определять биометрию как способ идентификации людей по одной или более физиологическим или поведенческим чертам.

Соответственно, можно выделить два вида биометрических признаков: статические и динамические. Первые человек приобретает от рождения, они почти не изменяются с течением времени (например, отпечатки пальцев, венозный рисунок лица, ДНК, радужная оболочка глаза и др. [40, с. 1]). Динамические признаки приобретаются со временем, они меняются в течение жизни (голос, походка, динамика воспроизведения подписи или набора текста на клавиатуре и др. $)^{22}$. Сегодня наиболее часто при биометрической идентификации используются отпечатки пальцев, голос, радужная оболочка глаза. По прогнозу международной консалтинговой компании J'son \& Partners Consulting, самыми быстро развивающимися биометрическими способами идентификации в ближайшие годы станет распознавание по радужной оболочке глаза, голосу и венозному рисунку ладони (рис. 3).

Следует отметить, что использование только одного биометрического параметра создает угрозу ложной идентификации другого пользователя либо же трудности идентификации вследствие существенного изменения данного параметра. В этой связи для повышения уровня достоверности необходимо использовать двух- и многофакторную идентификацию путем

\footnotetext{
${ }^{22}$ Обзор международного рынка биометрических технологий и их применение в финансовом секторе 2018 // Официальный сайт Центрального банка Российской Федерации. URL: https://www.cbr.ru/content/document/file/36012/rev_bio.pdf (дата обращения: 29.04.2020)
}

совмещения нескольких биометрических параметров, например голоса и отпечатков пальцев, что позволит обеспечить более высокий уровень надежности и безопасности биометрических систем.

В России запущен проект по формированию Единой биометрической системы. Его инициаторами выступили Банк России и Минкомсвязь России. Разработчиком и оператором системы является ПАО «Ростелеком» ${ }^{23}$. На сегодняшний день крупнейшие коммерческие банки России (такие как ПАО «Сбербанк», ПАО «ВТБ») продолжают работу по сбору биометрических данных граждан. Данная система обладает положительным потенциалом, прежде всего, для облегчения взаимодействий типа Government-toCitizen. Очевидное преимущество данной системы возможность получения услуг путем дистанционной аутентификации без личного посещения ведомства, что экономит временные ресурсы. Однако существуют и побочные эффекты. Так, ряд авторов и СМИ считают, что сбор биометрических данных подрывает конституционный принцип неприкосновенности частной жизни граждан, создает предпосылки жесткого информационного контроля над личностью и провоцирует черную торговлю данными о человеке ${ }^{24}[41$, с. 98-100].

Новое качество государственного управления - залог обеспечения конкурентоспособности национальной экономики и, следовательно, улучшения условий жизни населения России. Достигнуть этого можно путем реинжиниринга государственно-управленческих процессов и функций. Именно поэтому сегодня совершенствование отечественной инфраструктуры э-правительства является одним из приоритетных трендов социально-экономического развития Российской Федерации, а перечисленные выше решения частично нашли свое отражение в паспорте федерального проекта «Цифровое государственное управление», который является неотъемлемой частью национальной программы «Цифровая экономика Российской Федерации», разработанной во исполнение

\footnotetext{
${ }^{23}$ Официальный сайт Единой биометрической системы. URL: https://bio.rt.ru/ (дата обращения: 29.04.2020).

24 Это приведет к построению кастового общества // Официальный сайт информационно-аналитической службы «Русская народная линия». URL: https://ruskline.ru/news_rl/2018/03/23/ eto_privedet_k_postroeniyu_kastovogo_obwestva/ (дата обращения: 29.04.2020).
} 


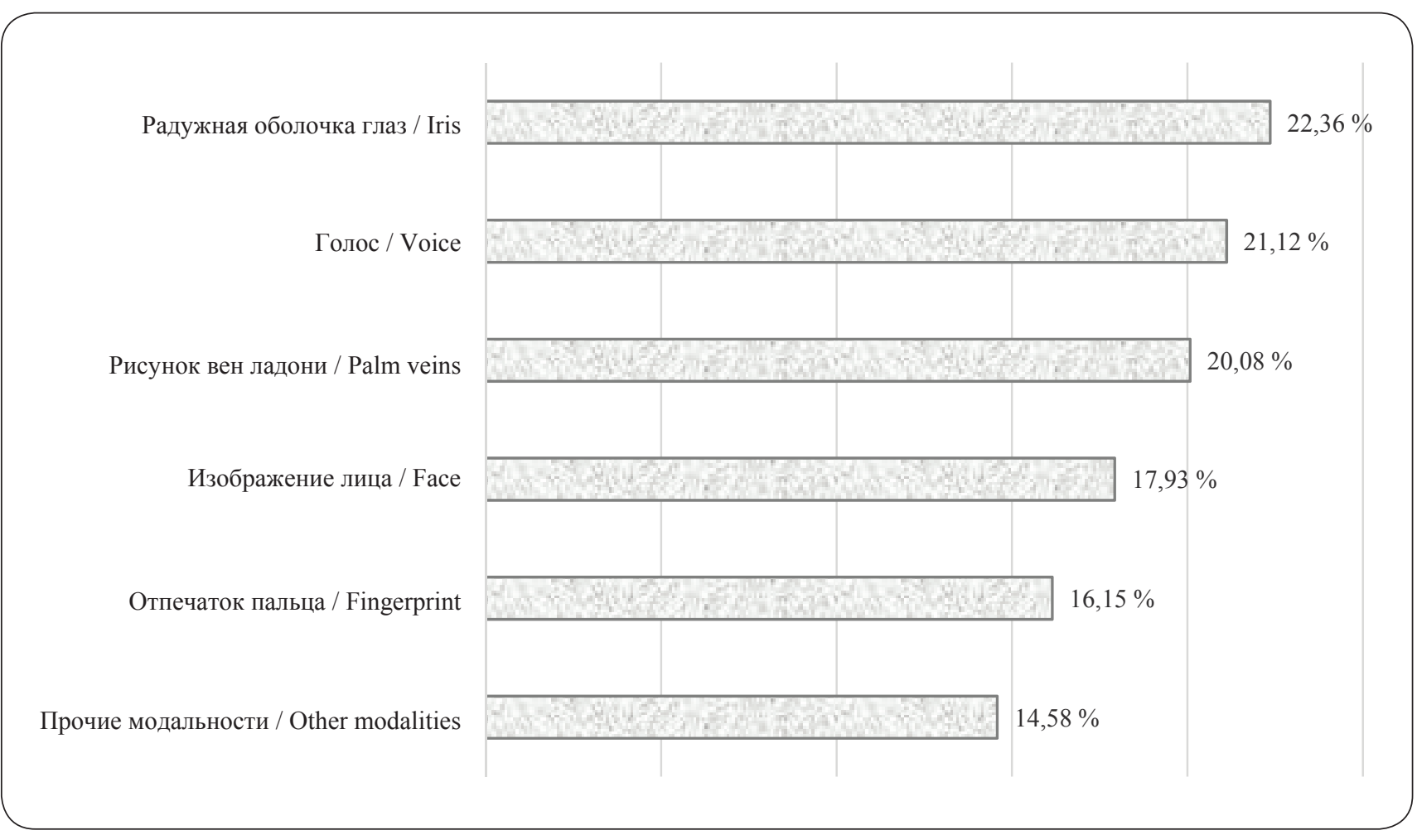

Рис. 3. Прогноз среднегодовых темпов роста рынка биометрических технологий до 2022 г.

Источник: Аналитический отчет «Мировой рынок биометрических систем, 2015-2022 гг.» // Официальный сайт J'son \& Partners Consulting. URL: http://json.tv/ict_telecom_analytics_view/mirovoy-rynok-biometricheskih-sistem-2015-2022-gg-20170119025618 (дата обращения: 29.04.2020).

\section{Fig. 3. Forecast for the average annual growth rate of biometric technologies market up to 2022}

Source: Analytical report "Global market of biometric systems, 2015-2022" // Official website of J'son \& Partners Consulting, available at: L: http://json.tv/ict_telecom_analytics_view/mirovoy-rynok-biometricheskih-sistem-2015-2022-gg-20170119025618 (access date: 29.04.2020).

абз. 10 пп. «б» п. 2 Указа Президента Российской Федерации от 7 мая 2018 г. № 204 «О национальных целях и стратегических задачах развития Российской Федерации на период до 2024 года».

\section{Выводы}

Итак, в настоящей работе рассмотрены некоторые проблемы, связанные с функционированием инфраструктуры э-правительства в России, а также предложены возможные пути их решения.

Упрощение процесса оказания сопутствующих услуг предлагается осуществить путем внедрения суперсервисов комплексного оказания услуг в соответствии с жизненной ситуацией.

Для минимизации количества документов на бумажном носителе предлагается перевести большин- ство публичных услуг, имеющих своим результатом выдачу заявителю документа, на реестровую модель.

В целях ликвидации проблемы разрозненности государственного интернет-пространства требуется создать единую точку доступа ко всем государственным ресурсам, унифицировать дизайн и форму организации публичных данных.

Оптимизировать внутриведомственный документооборот и обмен информацией между различными органами публичной власти можно путем создания единой облачной цифровой платформы данных, к которой имели бы оперативный доступ органы государственной власти и местного самоуправления.

В целях повышения удобства в процессе идентификации и аутентификации пользователей на Едином портале государственных услуг следует, во-первых, 
предоставить возможность дистанционного подтверждения личности при регистрации новых пользователей в ЕСИА; во-вторых, внедрять средства биометрической идентификации и аутентификации. Однако в этой области политика государства должна иметь просветительско-информационный характер: принудительное насаждение биометрии недопустимо по конституционно-правовым и морально-этическим соображениям.

Перечисленные предложения поспособствуют повышению качества как внутрисистемных взаимодействий (Government-to-Government и Government-
to-Employee), так и взаимодействий государства с гражданами, бизнесом и некоммерческими организациями (Government-to-Citizen, Government-toBusiness и Government-to-NGO).

Резюмируя вышеизложенное, можно констатировать, что Россия достигла существенного прогресса в сфере построения работоспособной инфраструктуры э-правительства, хотя по мере усложнения государственно-управленческих задач возникают новые вызовы, на которые необходимо отвечать инновационными решениями.

\section{Список литературы}

1. Киселев А. С. Современные теоретические подходы к понятию электронного государства // Актуальные проблемы российского права. 2018. № 6 (91). С. 32-39.

2. Олейник С. А., Мельничук М. А. Правовые основы деятельности электронного правительства в России и за рубежом и тенденции их развития // Вестник МИЭП. 2014. № 2 (15). С. 26-35.

3. Бондаренко С. В. Особенности формирования научного дискурса изучения «электронного правительства» / Многоликий дискурс / под общ. ред. В. Е. Хвощева и М. А. Малышева. Челябинск: Издательский центр ЮУрГУ, Изд-во НОЦ «КПОН», 2012. $671 \mathrm{c}$.

4. Comparative Perspectives on E-Government: Serving Today and Building for Tomorrow / P. Hernon, R. Cullen, H. C. Relye. Lanham, MD: Scarecrow Pre, 2006. 412 p.

5. Heeks R. Implementing and Managing eGovernment: An International Text. London: Sage Publications, 2006. 293 p.

6. The effects of e-government evaluation, trust and the digital divide in the levels of e-government use in European countries / R. Pérez-Morote, C. Pontones-Rosa, M. Núñez-Chicharro // Technological Forecasting and Social Change. 2020. Vol. 154. URL: http://www.sciencedirect.com/science/article/pii/S0040162519313150 (дата обращения: 29.04.2020).

7. Bannistera F., Connolly R. The great theory hunt: Does e-government really have a problem? // Government Information Quarterly. 2015. Vol. 32. Iss. 1. Pp. 1-11.

8. Богдановская И. Ю. Концепция «электронного государства» (сравнительно-правовые аспекты): доклад на IV Научнопрактической конференции «Право и Интернет: теория и практика». URL: https://www.ifap.ru/pi/04/r02.doc (дата обращения: 29.04.2020).

9. Sundberg L. Electronic government: Towards e-democracy or democracy at risk? // Safety Science. 2019. Vol. 118. Pp. $22-32$.

10. Grönlund Å., Horan T.A. Introducing e-Gov: History, Definitions, and Issues // Communications of the Association for Information Systems. 2005. Vol. 15. Pp. 713-729.

11. Bannistera F., Connolly R. The future ain't what it used to be: Forecasting the impact of ICT on the public sphere // Government Information Quarterly. 2020. Vol. 37. Iss. 1. Pp. 1-14.

12. Иншакова Е. Г. Электронное правительство в публичном управлении: монография. М.: Юрайт, 2018.139 с.

13. Бачило И. Л. Информационное право: учебник для академического бакалавриата. 5-е изд., перераб. и доп. М.: Юрайт, 2019. $419 \mathrm{c}$.

14. Ямщиков А. С., Баранов Д. А. Национальные системы электронного правительства: отечественный и зарубежный опыт // Научное обозрение. Экономические науки. URL: http://science-economy.ru/ru/article/view?id=921 (дата обращения: 29.04.2020).

15. Акопов Г. Л. Информационное право: учеб. пособие. Ростов н/Д: Феникс, 2008. 348 с.

16. Кузнецов П. У. Административная реформа в контексте формирования электронного правительства: терминологические проблемы // Российский юридический журнал. 2012. № 3. С. 37-47.

17. Акаткин Ю. М., Ясиновская Е. Д. Цифровая трансформация государственного управления: Датацентричность и семантическая интероперабельность / под науч. ред. и с предисл. В. А. Конявского. М.: ЛЕНАНД, 2019. 724 с.

18. Мандрыка Е. В. Технологии государственного управления в России // Вестник Института экономических исследований. 2017. № 1 (5). С. 138-145. 
19. Трегубова В. М. Электронное правительство как средство автоматизации процесса предоставления государственных услуг // Социально-экономические явления и процессы. 2011. № 3-4. С. 279-284.

20. Булгатова Ю. С., Дырхеев А. В. Информационные технологии как средство модернизации государственного управления в современном обществе // Вестник БГУ. Экономика и менеджмент. 2018. № 1. С. 8-15.

21. Чумаков Д. В. Электронное правительство как новый способ предоставления государственных услуг // Проблемы науки. 2016. № 34 (76). С. 69-71.

22. Кашина Е. А. Формирование электронного правительства в Российской Федерации: социально-политический аспект: дис. ... канд. полит. наук. М.: Рос. гос. социал. ун-т, 2009. 155 с.

23. Ронки А. Электронное правительство: эволюция или революция? Ч. 1 // Информационное общество. 2012. № 3. С. 10-22.

24. Сидорова А. А. Электронное правительство: учебник и практикум для бакалавриата и магистратуры. М.: Юрайт, 2018. $165 \mathrm{c}$.

25. Солодов В. В. E-government и борьба с коррупцией // Вестник Московского университета. Серия 21. Управление (государство и общество). 2006. № 1. С. 47-70.

26. Юртаев А. Н. Создание «электронного правительства» на региональном уровне как комплексная управленческая инновация // Вестник Московского университета. Серия 21. Управление (государство и общество). 2009. № 3. С. 3-15.

27. Васильева Е. Г., Кононенко Д. В. Современные интерпретации концепции электронного государства (электронного правительства) // Вестник Волгоградского государственного университета. Серия 5. Юриспруденция. 2016. № 1 (30). С. 9-16.

28. Лапочкин Р. А. Сравнительный анализ американской, континентально-европейской и азиатской моделей электронного правительства // Известия Орловского государственного технического университета. Серия: Информационные системы и технологии. 2008. № 1-2. С. 132-134.

29. Някина Е. С., Погодина Е. А. Анализ моделей электронного правительства // Государственное управление. Электронный вестник. 2013. № 36. С. 181-189.

30. Османов А. Э. К анализу современных моделей «электронного правительства» // Информационно-компьютерные технологии в экономике, образовании и социальной сфере. 2018. № 1 (19). С. 114-121.

31. Сединкин М. А. Возможности применения зарубежного опыта формирования электронного правительства в России // Вестник Адыгейского государственного университета. Серия 1: Регионоведение: философия, история, социология, юриспруденция, политология, культурология. 2011. № 3. С. 349-360.

32. Twizeyimana J. D., Andersson A. The public value of E-Government - A literature review // Government Information Quarterly. 2019. Vol. 36. Iss. 2. Pp. 167-178.

33. Атаисматов И. Электронное правительство // Наука и современность. 2016. № 48. С. 59-63.

34. Бонэм М., Сейферт Д. Потенциал «электронного правительства» // Государственное управление. Электронный вестник. 2003. № 2. С. 1-5.

35. Балюков А. С. Анализ актуальности создания электронного правительства // Вестник ЮУрГУ. Серия: Компьютерные технологии, управление, радиоэлектроника. 2014. № 3. С. 78-85.

36. Морозова М. А. Суперсервисы как способ цифровизации госуслуг // Хроноэкономика. 2019. № 6 (19). С. $55-59$.

37. Архипова 3. В. Трансформация «Электронного правительства» в «Цифровое правительство» // Известия БГУ. 2016. № 5. С. $818-824$.

38. Государство как платформа. (Кибер)государство для цифровой экономики. Цифровая трансформация / М. Петров, B. Буров, М. Шклярук, А. Шаров // Официальный сайт Центра стратегических разработок. URL: https://www.csr.ru/upload/ iblock/313/3132b2de9ccef0db1eecd56071b98f5f.pdf (дата обращения: 29.04.2020).

39. Lebovic N. Biometrics, or The Power of the Radical Center // The University of Chicago Press. 2015. Vol. 41 , № 4. Pp. 841-868.

40. Claypoole T., Stoll C. Developing Laws Address Flourishing Commercial Use of Biometric Information // Business Law Today. 2016. Pp. 1-5.

41. Соловьева А. А. Применение информационных технологий в целях идентификации граждан Российской Федерации: основные риски // Скиф. Вопросы студенческой науки. 2018. № 4 (20). С. 97-101.

\section{References}

1. Kiselev A. S. Modern theoretical approaches to the notion of an electronic government, Aktual'nye problemy rossiiskogo prava, 2018, No. 6 (91), pp. 32-39 (in Russ.).

2. Oleinik S. A., Mel'nichuk M. A. Legal bases of activity of an electronic government in Russia and abroad and trends of their development, Vestnik MIEP, 2014, No. 2 (15), pp. 26-35 (in Russ.).

Дворецкий А. А. Электронное правительство в современной России: инфраструктурные проблемь и пути их решения Dvoretskiy A. A. Electronic government in modern Russia: infrastructural problems and ways to solve them 
3. Bondarenko S. V. Features of forming a scientific discourse to study "an electronic government", Mnogolikii diskurs, monografiya, eds. V. E. Khvoshchev, M. A. Malyshev, Chelyabinsk, Izdatel'skii tsentr YuUrGU, Izd-vo NOTs "KPON", 2012, 671 p. (in Russ.).

4. Hernon P., Cullen R., Relye H. C. Comparative Perspectives on E-Government: Serving Today and Building for Tomorrow. Lanham, MD: Scarecrow Pre, 2006. 412 p.

5. Heeks R. Implementing and Managing eGovernment: An International Text, London, Sage Publica tions, 2006,293 p.

6. Pérez-Morote R., Pontones-Rosa C., Núñez-Chicharro M. The effects of e-government evaluation, trust and the digital divide in the levels of e-government use in European countries, Technological Forecasting and Social Change, 2020, Vol. 154, available at: http://www.sciencedirect.com/science/article/pii/S0040162519313150 (access date: 29.04.2020).

7. Bannistera F., Connolly R. The great theory hunt: Does e-government really have a problem?, Government Information Quarterly, 2015, Vol. 32, Iss. 1, pp. 1-11.

8. Bogdanovskaya I. Yu. Concept of "an electronic government" (comparative-legal aspects), Report at the $4^{\text {th }}$ Scientific-practical conference "Law and the Internet: theory and practice", available at: https://www.ifap.ru/pi/04/r02.doc (access date: 29.04.2020) (in Russ.).

9. Sundberg L. Electronic government: Towards e-democracy or democracy at risk?, Safety Science, 2019, Vol. 118, Pp. $22-32$.

10. Grönlund Å., Horan T.A. Introducing e-Gov: History, Definitions, and Issues, Communications of the Association for Information Systems, 2005, Vol. 15, pp. 713-729.

11. Bannistera F., Connolly R. The future ain't what it used to be: Forecasting the impact of ICT on the public sphere, Government Information Quarterly, 2020, Vol. 37, Iss. 1, pp. 1-14.

12. Inshakova E. G. Electronic government in public governance, Moscow, Yurait, 2018, 139 p. (in Russ.).

13. Bachilo I. L. Information law, Moscow, Yurait, 2019, 419 p. (in Russ.).

14. Yamshchikov A. S., Baranov D. A. National systems of an electronic government: Russian and foreign experience, Nauchnoe obozrenie. Ekonomicheskie nauki, available at: http://science-economy.ru/ru/article/view?id=921 (access date: 29.04.2020) (in Russ.).

15. Akopov G. L. Information law, Rostov on Don, Feniks, 2008, 348 p. (in Russ.).

16. Kuznetsov P. U. Administrative reform in the context of forming an electronic government: terminological isseus, Rossiiskii yuridicheskii zhurnal, 2012, No. 3, pp. 37-47 (in Russ.).

17. Akatkin Yu. M., Yasinovskaya E. D. Digital transformation of state governance: data centricity and semantic interoperability, ed. V. A. Konyavsky, Moscow, LENAND, 2019, 724 p. (in Russ.).

18. Mandryka E. V. Technologies of state governance in Russia, Vestnik Instituta ekonomicheskikh issledovanii, 2017, No. 1 (5), pp. 138-145 (in Russ.).

19. Tregubova V. M. An electronic government as a means of automating the process of providing state services, Sotsial'noekonomicheskie yavleniya i protsessy, 2011, No. 3-4, pp. 279-284 (in Russ.).

20. Bulgatova Yu. S., Dyrkheev A. V. Information technologies as a means modernization of state governance in the modern society, Vestnik BGU. Ekonomika i menedzhment, 2018, No. 1, pp. 8-15 (in Russ.).

21. Chumakov D. V. An electronic government as a new means of providing state services, Problemy nauki, 2016, No. 34 (76), pp. 69-71 (in Russ.)

22. Kashina E. A. Forming an electronic government in the Russian Federation: social-political aspect: a PhD (Politology) thesis, Moscow, Ros. gos. sotsial. un-t, 2009, 155 p. (in Russ.).

23. Ronki A. An electronic government: evolution or revolution? Part 1, Informatsionnoe obshchestvo, 2012, No. 3, pp. 10-22 (in Russ.).

24. Sidorova A. A. An electronic government: tutorial and practicum for Bachelor and Master courses, Moscow, Yurait, 2018, 165 p. (in Russ.).

25. Solodov V. V. E-government and struggling against corruption, Vestnik Moskovskogo universiteta, Ser. 21, Upravlenie (gosudarstvo i obshchestvo), 2006, No. 1, pp. 47-70 (in Russ.).

26. Yurtaev A. N. Creating "an electronic government" at the regional level as a complex managerial innovation, Vestnik Moskovskogo universiteta. Ser. 21. Upravlenie (gosudarstvo i obshchestvo), 2009, No. 3, pp. 3-15 (in Russ.).

27. Vasil'eva E. G., Kononenko D. V. Modern interpretations of the concept of an electronic state (an electronic government), Vestnik Volgogradskogo gosudarstvennogo universiteta. Ser. 5 Yurisprudentsiya, 2016, No. 1 (30), pp. $9-16$ (in Russ.).

28. Lapochkin R. A. Comparative analysis of the American, continental European and Asian models of an electronic government, Izvestiya Orlovskogo gosudarstvennogo tekhnicheskogo universiteta. Ser. Informatsionnye sistemy i tekhnologii, 2008, No. 1-2, pp. 132-134 (in Russ.).

29. Nyakina E. S., Pogodina E. A. Analysis of the models of an electronic government, Gosudarstvennoe upravlenie. Elektronnyi vestnik, 2013, No. 36, pp. 181-189 (in Russ.). 
30. Osmanov A. E. On the analysis of modern models of "an electronic government", Informatsionno-komp'yuternye tekhnologii v ekonomike, obrazovanii i sotsial'noi sfere, 2018, No. 1 (19), pp. 114-121 (in Russ.).

31. Sedinkin M. A. Possibilities for applying the foreign experience of forming an electronic government in Russia, Vestnik Adygeiskogo gosudarstvennogo universiteta. Ser. 1. Regionovedenie: filosofiya, istoriya, sotsiologiya, yurisprudentsiya, politologiya, kul'turologiya, 2011, No. 3, pp. 349-360 (in Russ.).

32. Twizeyimana J. D., Andersson A. The public value of E-Government - A literature review, Government Information Quarterly, 2019, Vol. 36, Iss. 2, pp. 167-178.

33. Ataismatov I. Electronic government, Nauka i sovremennost', 2016, No. 48, pp. 59-63 (in Russ.).

34. Bonem M., Seifert D. Potential of "electronic government", Gosudarstvennoe upravlenie. Elektronnyi vestnik, 2003, No. 2 , pp. 1-5 (in Russ.).

35. Balyukov A. S. Analysis of the topicality of "electronic government" formation, Vestnik YuUrGU. Ser. Komp'yuternye tekhnologii, upravlenie, radioelektronika, 2014, No. 3, pp. 78-85 (in Russ.).

36. Morozova M. A. Superservices as a means of state services digitalization, Khronoekonomika, 2019, No. 6 (19), pp. 55-59 (in Russ.).

37. Arkhipova Z. V. Transformation of an "electronic government" into "digital government", Izvestiya BGU, 2016, No. 5, pp. 818-824 (in Russ.).

38. Petrov M., Burov V., Shklyaruk M., Sharov A. State as a platform. (Cyber)state for the digital economy. Digital transformation, Ofitsial'nyi sait Tsentra strategicheskikh razrabotok, available at: https://www.csr.ru/upload/iblock/313/3132b2de9ccef0db1 eecd5 6071b98f5f.pdf (access date: 29.04.2020) (in Russ.).

39. Lebovic N. Biometrics, or The Power of the Radical Center, The University of Chicago Press, 2015, Vol. 41, No. 4, pp. 841-868.

40. Claypoole T., Stoll C. Developing Laws Address Flourishing Commercial Use of Biometric Information, Business Law Today, 2016, pp. 1-5.

41. Solov'eva A. A. Applying information technologies for identification of the Russian Federation citizens: main risks, Skif. Voprosy studencheskoi nauki, 2018, No. 4 (20), pp. 97-101 (in Russ.). 